\title{
Construction of a Dual-Fluorescence Reporter System to Monitor the Dynamic Progression of Pluripotent Cell Differentiation
}

\author{
Wu-Sheng Sun, ${ }^{1,2}$ Ju-Lan Chun, ${ }^{2}$ Jeong-Tae Do, ${ }^{3}$ Dong-Hwan Kim, ${ }^{1}$ Jin-Seop Ahn, ${ }^{1}$ \\ Min-Kyu Kim, ${ }^{2}$ In-Sul Hwang, ${ }^{4}$ Dae-Jin Kwon, ${ }^{4}$ Seong-Soo Hwang, ${ }^{4}$ and Jeong-Woong Lee ${ }^{1}$ \\ ${ }^{1}$ Biotherapeutics Translational Research Center, Korea Research Institute of Bioscience and Biotechnology, \\ Daejeon 305-806, Republic of Korea \\ ${ }^{2}$ Department of Animal Science and Biotechnology, College of Agriculture and Life Science, Chungnam National University, \\ Daejeon 305-764, Republic of Korea \\ ${ }^{3}$ Department of Stem Cell and Regenerative Biology, College of Animal Bioscience and Technology, Konkuk University, \\ Seoul, Republic of Korea \\ ${ }^{4}$ Animal Biotechnology Division, National Institute of Animal Science, Wanju 565-851, Republic of Korea \\ Correspondence should be addressed to Seong-Soo Hwang; hwangss@korea.kr and Jeong-Woong Lee; jwlee@kribb.re.kr
}

Received 17 August 2016; Revised 6 October 2016; Accepted 18 October 2016

Academic Editor: Gary E. Lyons

Copyright (C) 2016 Wu-Sheng Sun et al. This is an open access article distributed under the Creative Commons Attribution License, which permits unrestricted use, distribution, and reproduction in any medium, provided the original work is properly cited.

Oct4 is a crucial germ line-specific transcription factor expressed in different pluripotent cells and downregulated in the process of differentiation. There are two conserved enhancers, called the distal enhancer (DE) and proximal enhancer (PE), in the $5^{\prime}$ upstream regulatory sequences (URSs) of the mouse Oct4 gene, which were demonstrated to control Oct4 expression independently in embryonic stem cells (ESCs) and epiblast stem cells (EpiSCs). We analyzed the URSs of the pig Oct4 and identified two similar enhancers that were highly consistent with the mouse DE and PE. A dual-fluorescence reporter was later constructed by combining a DE-free-Oct4-promoter-driven EGFP reporter cassette with a PE-free-Oct4-promoter-driven mCherry reporter cassette. Then, it was tested in a mouse ESC-like cell line (F9) and a mouse EpiSC-like cell line (P19) before it is formally used for pig. As a result, a higher red fluorescence was observed in F9 cells, while green fluorescence was primarily detected in P19 cells. This fluorescence expression pattern in the two cell lines was consistent with that in the early naïve pluripotent state and late primed pluripotent state during differentiation of mouse ESCs. Hence, this reporter system will be a convenient tool for screening out ESC-like naïve pluripotent stem cells from other metastable state cells in a heterogenous population.

\section{Introduction}

The population in a culture of pluripotent cells is not homogenous; therefore, an appropriate reporter system, which can screen out the pluripotent stem cell (PSCs) from other metastable stem cells or even completely differentiated somatic cells, is necessary. To date, many reporters have been constructed by combining the promoter from candidate pluripotent genes, such as Nanog [1], Rex-1 [2], or Oct4 [3] and a fluorescent protein. Next, by monitoring the fluorescence signal, the expression of pluripotency-related genes could be determined and the pluripotent cells could be easily isolated from the heterogenous cell population without additional staining processes [4].

Oct4 (also known as Oct3 or POU5F1) is one of the wellknown reporter genes because its expression is restricted in pluripotent cells and germ cells [5]. Upon differentiation of PSCs, Oct4 expression was gradually reduced and finally silenced along with epigenetic modifications [6]. The silenced Oct4 in differentiated somatic cells can be reactivated by several reprogramming processes such as fusion-induced reprogramming, somatic cell nuclear transfer (SCNT), or generation of induced pluripotent stem cells (iPSCs) [7, 8], suggesting the importance of Oct4 in maintenance and 
self-renewal of pluripotent cells. An Oct4 reporter system, constructed by integrating the Oct4 promoter into GFP, can be used as an efficient marker to mimic the endogenous Oct4 gene expression in mouse [9]. So far, a variety of Oct4promoter-driven GFP or EGFP reporters have been used in mouse $[10,11]$, human $[12,13]$, cattle $[14,15]$, rabbit $[16,17]$, zebrafish [18], medaka [19], and pig [20, 21] models.

PSCs have been classified into at least two states: naïve and primed pluripotent states [22, 23]. Mouse embryonic stem cells (mESCs) are referred to as an earlier or naïve pluripotent state, while mouse epiblast stem cells (EpiSCs) correspond to a later or "primed" pluripotent state. All of the cells of the two types of pluripotent stem cells express pluripotency genes, such as Oct4 and Nanog, and can differentiate into cells of all three germ layers in vitro, but they are also distinct in many aspects. Naïve PSCs are characterized by formation of compact and dome-like colonies [24], are dependent on leukemia inhibitory factor (LIF) [25], contain two active X chromosomes (XaXa) [26, 27], and, most notably, efficiently contribute to chimeras [28]. In contrast, primed PSCs form flat colonies, respond to basic fibroblast growth factor (bFGF) and activin instead of LIF, and have an inactivated X chromosome (XaXi) [28, 29].

To distinguish between naïve and primed PSCs, transcriptome analysis [30] or immunostaining has typically been conducted. However, little is known about porcine-specific pluripotency markers, which is a basic obstacle to studying PSCs in pigs using this approach [4]. Oct4-GFP reporter systems can be a good marker for PSC studies [31], but Oct4-GFP itself seems infeasible for categorizing the two PSC types because Oct4 is expressed in both naïve and primed PSCs [32]. Interestingly, previous reports indicated that the expression of mouse Oct4 in the two different PSC states is regulated by two independent enhancers. In naïve PSCs, Oct4 was primarily controlled by the distal enhancer (DE), whereas, in primed PSCs, it is driven by its proximal enhancer (PE) [33, 34]. Based on these studies, we established a dual reporter system using the DE or PE deleted upstream regulatory sequences (URSs) of pig Oct4 to drive EGFP and mCherry (RFP) gene expression. Before this reporter is directly used in pig, firstly, we tested it in three types of defined mouse PSCs with different levels of pluripotency. We expect that this reporter system can be a useful tool for screening out naïve PSCs from primed PSCs and for monitoring the dynamic progression of cell differentiation.

\section{Materials and Methods}

The use of animals in this study was approved by the Institutional Animal Care Committee of the Korea Research Institute of Bioscience and Biotechnology and the current guidelines on animal care were followed. All chemicals used in this study were purchased from Sigma Aldrich (USA), unless otherwise stated.

2.1. Alignment of Oct4 URSs in Cow, Human, Mouse, and Pig. The sequences of the Oct4 URS for cow (chr23: 27,766,78227,769,892), human (chr6: 31,170,621-31,173,790), mouse (chr17: 35,503,313-35,506,099), and pig (chr7: 27,259,93227,262,689) were obtained from UCSC (https://genome.ucsc .edu/). The sequences in the gap region in the cow Oct4 URS (chr23: 27,766,985-27,767,084) was obtained from previous study [36]. Comparison of each sequence was performed with DNAMAN (Lynnon Biosoft, USA). The conserved region was found with the mVISTA program in LAGAN mode with default parameters [37]. Additional 1,000 bp sequences downstream of the translation initiation site of the Oct4 gene were selected together with their URS mentioned above and, when analyzed, the distribution of the $\mathrm{CpG}$ islands was used as a reference [38].

\subsection{Construction of Porcine Oct4-EGFP/mCherry Reporter} Vectors. Pig umbilical cord was collected from the National Institute of Animal Science (Suwon, Korea). The collected tissue was taken to the laboratory and immediately washed twice with Dulbecco's phosphate-buffered saline (DPBS) (Welgene, Korea) and frozen in liquid nitrogen until used for DNA isolation. A $5.6 \mathrm{kbp}$ regulatory region of the porcine Oct4 gene that includes all 4 regions conserved among human and mouse genes was divided into $2.5 \mathrm{kbp}$ and $3.1 \mathrm{kbp}$ segment for easy cloning. Briefly, porcine genomic DNA was extracted using a genomic DNA extraction kit (Qiagen, Germany) according to the manufacturer's protocol. The $3.1 \mathrm{kbp}$ segment was cloned and inserted into a pEGFP-C2 vector (Clontech, Japan) to replace the original CMV promoter, as reported previously, to construct the $\mathrm{pOg} 2$ vector [21]. Next, the $2.5 \mathrm{kbp}$ segment was amplified by PCR using a $2.5 \mathrm{Up}$ primer set (Table 1) under an initial denaturation of $3 \mathrm{~min}$ at $94^{\circ} \mathrm{C}, 35$ cycles of $30 \mathrm{~s}$ at $94^{\circ} \mathrm{C}, 30 \mathrm{~s}$ at $54^{\circ} \mathrm{C}, 3 \mathrm{~min}$ at $72^{\circ} \mathrm{C}$, and a final extension of $5 \mathrm{~min}$ at $72^{\circ} \mathrm{C}$. Next, the $2.5 \mathrm{kbp}$ amplicon was inserted upstream of the $3.1 \mathrm{kbp}$ segment in the pOg2 vector at the AseI site (appears in lower-case letters in the primer in Table 1) to construct the pOG2 vector. The pOm2 vector was constructed by replacing the EGFP gene between the Age1 and Kpn1 site in the pOG2 vector with the corresponding mCherry CDS in the pmCherry-C1 vector (Clontech, Japan).

2.3. Construction of the Cell-Type-Specific Reporter Vector. A $351 \mathrm{bp}$ segment of the DE1 region (primer set DE1), a 197 bp segment of the DE2 region (primer set DE2), a 164 bp segment of the PE1 region (primer set PE1), and a $759 \mathrm{bp}$ segment of the PE2 region (primer set PE2) were amplified by a high fidelity npfu DNA polymerase (Enzynomics, Korea). The PCR was performed as follows: 1 cycle of $3 \mathrm{~min}$ at $94^{\circ} \mathrm{C}$ for denaturation, 35 cycles of $30 \mathrm{~s}$ at $94^{\circ} \mathrm{C}, 30 \mathrm{~s}$ at $55^{\circ} \mathrm{C}, 30 \mathrm{~s}$ at $72^{\circ} \mathrm{C}$, and 1 final cycle of $2 \mathrm{~min}$ at $72^{\circ} \mathrm{C}$. Then, the four amplified products were purified with a Gel Purification Kit (Bioneer, Korea) followed by digestion with the restriction enzyme SalI (appears in lower-case letters in each primer in Table 1). Next, a 1:1 mixture of DE1/DE2 was used as a template for amplifying a $554 \mathrm{bp}$ segment of $\triangle \mathrm{DE}$ with DE1$\mathrm{F}$ and $\mathrm{DE} 2-\mathrm{R}$ primers. In the same manner, a $1: 1$ mixture of PE1/PE2 was used as the template for amplifying $888 \mathrm{bp}$ of $\triangle \mathrm{PE}$ with $\mathrm{PE} 1-\mathrm{F}$ and $\mathrm{PE} 2-\mathrm{R}$ primers. The PCR reactions were performed as follows: 1 cycle of $3 \mathrm{~min}$ at $94^{\circ} \mathrm{C}$ for 
TABLE 1: List of primers used in this study.

\begin{tabular}{|c|c|c|c|}
\hline Primers & Sequences* & Primer length (bp) & Amplicon size (bp) \\
\hline $2.5 \mathrm{Up}-\mathrm{F}$ & $5^{\prime}$-attaatTGTGAGCACAGTTCCATCCTGACC - $3^{\prime}$ & 30 & \multirow{2}{*}{2526} \\
\hline $2.5 \mathrm{Up}-\mathrm{R}$ & $5^{\prime}$-attaatCCAGCTGAAATGACTCCTGGGGAA - $3^{\prime}$ & 30 & \\
\hline DEl-F & $5^{\prime}$-GCTTGTCCTTAAGGTTCTGGGTCA-3' & 24 & \multirow{2}{*}{351} \\
\hline DE1-R & $5^{\prime}$-gtcgacATCTACTGCTGAGCTCCTTGGCTC-3' & 30 & \\
\hline DE2-F & $5^{\prime}$-gtcgacGAAGCACATCTTTCСАСССССАСС-3' & 30 & \multirow{2}{*}{683} \\
\hline DE2-R & $5^{\prime}$-СTCСTCTGAATCTCTTCCAGTGCC-3' & 24 & \\
\hline PEI-F & $5^{\prime}$-TTTTCGCTAGCCCCCCAAACAAAG-3' & 24 & \multirow{2}{*}{164} \\
\hline PE1-R & $5^{\prime}$-gtcgacTCACACAGAATCCCCTTCAGAGCA-3' & 30 & \\
\hline PE2-F & 5' -gtcgacТСТСССССССАССТСССТССТТ- $3^{\prime}$ & 28 & \multirow{2}{*}{759} \\
\hline PE2-R & $5^{\prime}$-GGTGTCTCGAGGGCGAAAGTCGGA-3' & 24 & \\
\hline AscI adaptor & $5^{\prime}$-TAATggcgcgccAT- $3^{\prime}$ & 14 & - \\
\hline
\end{tabular}

${ }^{*}$ Restriction enzyme sites are shown in lowercase. F: forward; R: reverse; DE: distal enhancer; PE: proximal enhancer.

denaturation, 35 cycles of $30 \mathrm{~s}$ at $94^{\circ} \mathrm{C}, 30 \mathrm{~s}$ at $65^{\circ} \mathrm{C}, 30 \mathrm{~s}$ at $72^{\circ} \mathrm{C}$, and 1 final cycle of $2 \mathrm{~min}$ at $72^{\circ} \mathrm{C}$.

Subsequently, the region between the AfIII and XmnI sites in pOG2 was replaced by the cloned $\triangle \mathrm{DE}$ to construct the $\triangle \mathrm{DE}-\mathrm{pOG} 2$ vector. The region between the NheI and SmaI sites in $\mathrm{pOm} 2$ was replaced by the cloned $\triangle \mathrm{PE}$ to construct the $\triangle \mathrm{PE}-\mathrm{pOm} 2$ vector. The sequence between the AgeI and $K p n I$ sites in $\mathrm{pOm} 2$ was replaced by the EGFP CDS region in pEGFP-C2 to construct the $\triangle$ PE-pOG2 vector. Then, an AscI site was added to the $\triangle \mathrm{DE}$-pOG2 and $\triangle \mathrm{PE}$-pOm2 vectors by inserting an AscI adaptor (Table 1) before the AseI site. Finally, the region from the AscI site to the RsrII site in the $\triangle \mathrm{DE}-\mathrm{pOG} 2$ vector and the region from the RsrII site to the MluI site in the $\triangle \mathrm{PE}-\mathrm{pOm} 2$ vector were ligated to complete the construction of the $\Delta \mathrm{DE}-\mathrm{pOG} 2-\Delta \mathrm{PE}-\mathrm{pOm} 2$ dual-fluorescence reporter vector (Figure 3(a)).

2.4. Cell Culture and Transfection. The F9 mouse teratocarcinoma cells were cultured in Dulbecco's modified Eagle's medium (DMEM) (Welgene Inc., Korea) supplemented with $10 \%$ fetal bovine serum (Gibco, USA), 100 units $/ \mathrm{mL}$ of penicillin, and $100 \mu \mathrm{g} / \mathrm{mL}$ of streptomycin (Gibco, USA). The P19 mouse carcinoma cells were cultured in alpha minimum essential medium (Gibco, USA) supplemented with $10 \%$ FBS, 1x nonessential amino acids (NEAA) (Gibco, USA), 100 units $/ \mathrm{mL}$ of penicillin, and $100 \mu \mathrm{g} / \mathrm{mL}$ of streptomycin. J1 mouse ESCs were cultured in DMEM supplemented with 15\% ES FBS (Gibco, USA), 1x GlutaMAX (Gibco, USA), $100 \mu \mathrm{M} \beta$-mercaptoethanol (Gibco, USA), $1 \mathrm{mM}$ sodium pyruvate (Gibco, USA), 1x NEAA, 1000 units/mL of leukemia inhibitory factor (LIF) (Chemicon, USA), and 100 units $/ \mathrm{mL}$ of penicillin and $100 \mu \mathrm{g} / \mathrm{mL}$ of streptomycin. The cells were fed every day and split every second day with a 1:5 split ratio. All of the three cell lines were cultured on $0.1 \%(\mathrm{w} / \mathrm{v})$ gelatin coated dishes or plates.

For transfection, briefly, $4 \mu \mathrm{g}$ of plasmid DNA was transfected into P19 cells in a 6-well plate using lipofectamine LTX (Invitrogen, USA) according to the manufacturer's protocol. Similarly, $1 \mu \mathrm{g}$ of plasmid DNA was transfected into $\mathrm{J} 1$ cells and F9 cells by effectene reagent (Qiagen, Germany) according to a previously described procedure [35]. For the promoter activity assay, the fluorescence intensity of transfected cells in each well was measured by VictorX multilabel readers (PerkinElmer, USA). For transgenic cell line establishment, the fluorescence-positive cell colonies were picked using a plain capillary tube (Kimble Chase, USA) under an inverted fluorescence microscope (Axiovert 200M, Carl Zeiss, Germany), cultured, and routinely passaged every 2 days.

2.5. Alkaline Phosphatase (AP) Staining. Alkaline phosphatase (AP) staining was performed according to a previously reported procedure [39] using the BCIP ${ }^{\circledR} / \mathrm{NBT}$ Liquid Substrate System (Sigma, USA). First, the cells were washed with DPBS once, followed by fixation with $10 \%$ neutral buffered formalin (Sigma, USA) at room temperature for $30 \mathrm{~min}$. After washing three times with Tris buffer solution, $1 \mathrm{~mL}$ of BCIP/NBT was added into each well of the 6-well plate. Next, the plate was slowly rocked at room temperature for approximately $30 \mathrm{~min}$ and then imaged.

2.6. Total RNA Extraction and RT-PCR. Total RNA was isolated from the transgenic cell lines using the Trizol reagent (Invitrogen, USA) according to the manufacturer's protocol. The cDNA was synthesized using TOPscript Reverse Transcription kit (Enzynomics, Korea). The expression levels of EGFP, mCherry, Oct4, Sox2, Klf4, c-Myc, and Nanog mRNA were detected by RT-PCR. The reaction was performed as follows: 30 cycles of $30 \mathrm{~s}$ for denaturation at $94^{\circ} \mathrm{C}, 30 \mathrm{~s}$ annealing at $62^{\circ} \mathrm{C}$, and $30 \mathrm{~s}$ extension at $72^{\circ} \mathrm{C}$. The relative expression of GAPDH was used as an internal control.

2.7. Immunofluorescent Cytochemical Staining (ICC). The transgenic cells were seeded in a 6-well plate and cultured until cell colonies formed. Then, the cells were fixed with 4\% paraformaldehyde (Sigma, USA) for $15 \mathrm{~min}$ at room temperature and permeabilized with $0.25 \%$ TRITON $^{\mathrm{TM}} \mathrm{X}$ 100 (Promega, USA) in DPBS for $15 \mathrm{~min}$. Subsequently, the cells were blocked with $1 \mathrm{x}$ blocking solution (DaeMyung Science, Korea) for $1 \mathrm{~h}$ at room temperature and incubated with anti-Nanog (1:500 dilution; Abcam, UK) or anti-Oct4 (1:50 dilution; Abcam, UK) at $4^{\circ} \mathrm{C}$ in $1 \mathrm{x}$ blocking solution 
overnight. After washing three times with $1 x$ phosphatebuffered saline with Tween 20 (LPS solution, Korea), the cells were incubated with AlexaFluor ${ }^{\circledR} 555$-conjugated secondary antibodies (Invitrogen, USA) for $2 \mathrm{~h}$ at room temperature. Finally, the nuclei were stained with $5 \mu \mathrm{g} / \mathrm{mL}$ Hoechst 33342 solution (Sigma, USA) for $5 \mathrm{~min}$ at room temperature. Cell images were acquired using an Axiovert 200M system (Carl Zeiss, Germany).

2.8. Statistical Analysis. All the experiments were performed in duplicate. The results are shown as the mean \pm SEM. A $p$ value $<0.05$ denotes a difference possessing statistical significance. The fluorescence intensity of the pictures was converted to corrected total cell fluorescence (CTCF) by Image $\mathrm{J} 2 \mathrm{x}$ as previously described [40]. CTCF $=$ integrated density - (area of selected cell $\times$ mean fluorescence of background readings). The data were analyzed by SPSS17.0 using Duncan's multiple comparison tests or Student's $t$-test.

\section{Results}

3.1. Four Conserved Regions Were Identified in the Pig Oct4 URS. The URS of the porcine Oct4 gene was successfully cloned from the umbilical cord. DNA sequence analysis showed that it shared relatively low homology with that of the human $(43.11 \%)$, cow $(38.71 \%)$, and mouse $(34.66 \%)$ gene (Figure 1(a)). In particular, the distribution pattern of CpGs appeared unique in the porcine Oct4 URS, and three $\mathrm{CpG}$ islands were only predicted around pig Oct4 proximal promoter (PP) (Figure 1(b)). However, comparative analysis identified four highly conserved regions (CR1, CR2, CR3, and CR4) and three functional elements, the distal enhancer (DE), the proximal enhancer (PE), and the PP in the pig Oct4 URS, which were similar to those found in the human, mouse, and cow gene (Figure 1(c); see Supplementary Figure 1 in Supplementary Material available online at http:// dx.doi.org/10.1155/2016/1390284). The sequence similarity in CR1, CR2, CR3, and CR4 is as high as 91.73\%, 94.88\%, $87.19 \%$, and $82.86 \%$, respectively. The CR1 region could be the most crucial part for Oct4 expression because the minimal proximal promoter, transcriptional binding sites of Sp1/Sp3, and the hormone responsive elements (HRE) were located within it (Supplementary Figure 1). The DE was located within the CR4 region and the PE was located within the CR2 region (Supplementary Figure 1).

\subsection{Pig Oct4 Expression Is Regulated by Two Cell-Type-} Specific Enhancers. In order to find the functional regulatory elements in the porcine Oct4 URS, we constructed four EGFP reporter vectors carrying different Oct4 URS lengths. Here, we used 3 types of mouse PSCs to test this reporter system. After transfection, we found that EGFP, which was controlled by the entire $5.6 \mathrm{~kb}$ long URS (pOG2 vector) containing all of the 4 conserved regions, was strongly expressed in F9 cells and P19 cells (Figures 2(a) and 2(b)). When the $2.5 \mathrm{~kb}$ $5^{\prime}$-flanking region was removed ( $\mathrm{pOg} 2$ vector), there was no substantial impact on its regulatory activity. However, deletion of the $\mathrm{DE}$ region $(\triangle \mathrm{DE}-\mathrm{pOG} 2$ vector) resulted in an obvious attenuation of the fluorescence signal in F9 cells $(p<$ 0.05 ) but had no significant effect on P19 cells (Figure 2(b)). Conversely, the fluorescence signal was significantly reduced only in P19 cells $(p<0.05)$ when transfected by the $\triangle \mathrm{PE}-\mathrm{pOG} 2$ vector (Figure 2(b)). These changes in EGFP expression demonstrated that the expression of Oct4 is predominantly dependent on the DE in F9 cells rather than the $\mathrm{PE}$, while $\mathrm{PE}$ is the predominant regulatory region in $\mathrm{P} 19$ cells for Oct4 expression.

3.3. Establishment of Transgenic Cell Lines Stably Expressing EGFP and RFP. F9 cells, P19 cells, and mESCs were transfected by the linearized dual-fluorescence reporter vector, $\triangle \mathrm{DE}$-pOG2- $\triangle \mathrm{PE}-\mathrm{pOm} 2$ (Figure 3(a)). The fluorescencepositive cells were propagated, genotyped, and established as cell lines (Figure 3(b)). To confirm the pluripotency of these transgenic cell lines, the expression of pluripotency markers (Figure 3(c)), and alkaline phosphatase activity were observed (Figure 3(d)). As expected, all of the three transgenic cell lines were shaded by the alkaline phosphatase reaction substrates, BCIP/NBT (Figure 3(e)). Immunofluorescent cytochemical staining analysis showed that the three transgenic cell lines expressed typical pluripotency markers, such as Nanog and Oct4 (Figure 3(e)).

3.4. Testing the Dual-Fluorescence Reporter System in Two Kinds of Defined PSCs. To determine whether the ESC-stagelike F9 cells and epiblast-stage-like P19 cells can be distinguished by the two transgenes, the fluorescence expression pattern in the 2 transgenic cell lines was determined. As we expected, the fluorescence intensity in the two types of cells was very different (Figures 4(a) and 4(b)). There was a relatively higher red fluorescence signal observed in F9 cells, while green fluorescence was primarily detected in P19 cells (Figures 4(a) and 4(b)). However, the negative control cell line, MEFs, exhibited neither green nor red fluorescence expression. This result demonstrated that our dualfluorescence reporter could be an efficient tool to monitor the different states of PSCs.

3.5. Classifying mESCs from a Heterogenous Population by Dual-Fluorescence Signals. Typically, mESCs are considered to be in a heterogenous state containing several intermediate unstable cell types because of spontaneous differentiation. We checked the morphology of each cell colony and found that most of them had a three-dimensional dome-like morphology with well-defined edges (Figure 5(a)(1)), but some of them were flattened colonies with smooth edges (Figure 5(a)(2) and Figure 5(a)(3)), and a small fraction of colonies appeared damaged with jagged rough edges (Figure 5(a)(4)). Accordingly, the fluorescence expression pattern in each cell colony was determined. As a result, at least four types of colonies were identified in transgenic mESCs (Figure 5(a)(2) and Figure 5(a)(3)). A relatively higher level of red fluorescence was detected in Type I colonies. Similar levels of green and red fluorescence were detected in Type II colonies. A relatively higher level of green fluorescence was detected in Type III colonies and neither green nor red 


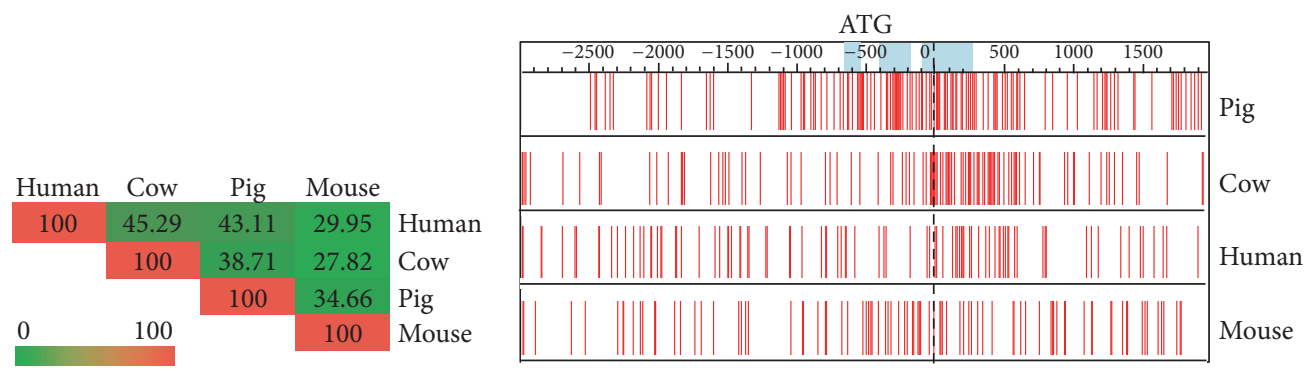

(a)

(b)

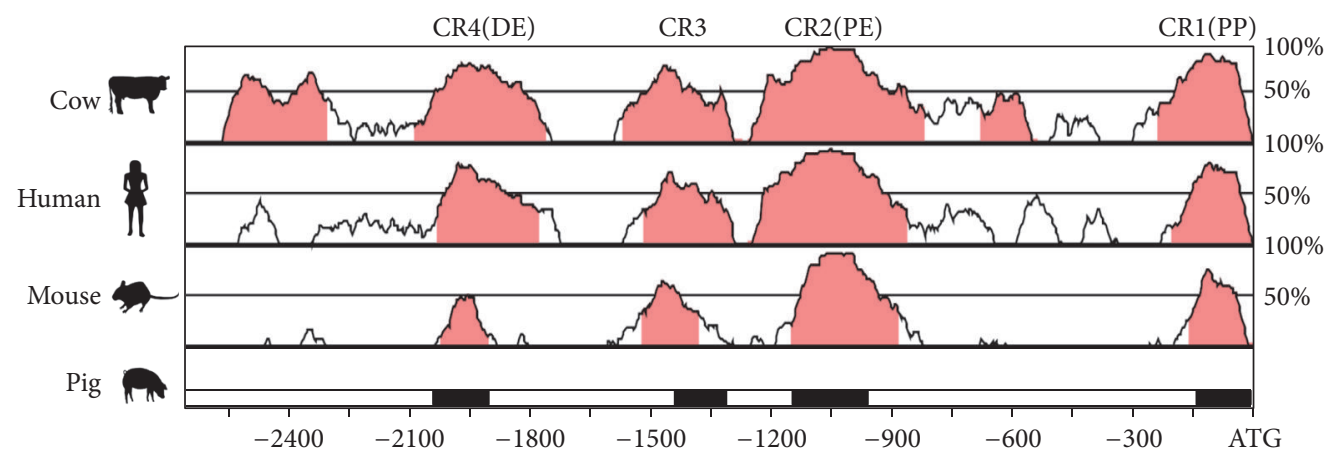

(c)

FIGURE 1: Alignment of the human, cow, mouse, and pig Oct4 gene and its upstream regulatory sequences (URSs). (a) Pig URS shares relatively low homology with the human (43.11\%), cow (38.71\%), and mouse (34.66\%) gene, respectively. (b) The distribution of CpGs is obviously higher in the porcine Oct4 URS, and three CpG islands appear to exist only in pig but are rarely present in the human, mouse, and cow gene. Red bars at the bottom show the CpG dinucleotide. Light blue shaded regions are the predicted CpG islands. (c) Four highly conserved blocks (CR1, CR2, CR3, and CR4) in pig were found with homologies from $87.19 \%$ to $94.88 \%$ through pairwise alignments. The right axis indicates the percentage identity within a $100 \mathrm{bp}$ window for each pairwise comparison, ranging from $10 \%$ to $100 \%$. Regions sharing greater than $25 \%$ identity are shaded and the black horizontal line indicates 50\% identity. CR: conserved region. DE: distal enhancer. PE: proximal enhancer. PP: minimal proximal promoter.

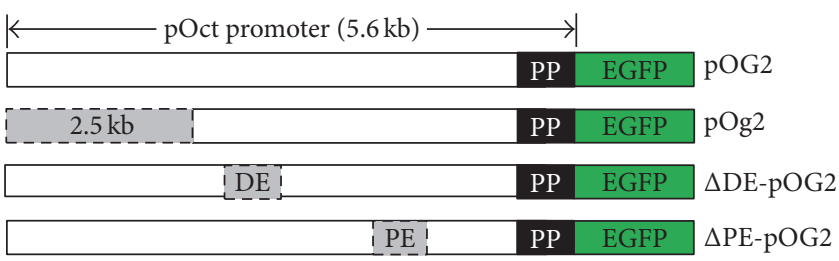

(a)

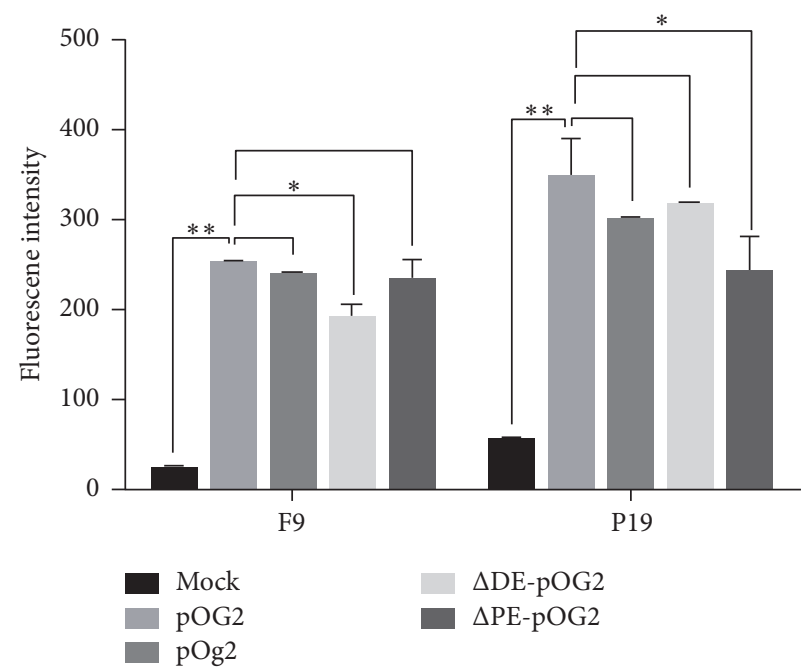

(b)

FIGURE 2: Promoter activity assay for the pig Oct4 promoter. (a) Four EGFP reporter vectors carrying different lengths of the pig Oct4 URS were constructed from a pEGFP-C2 vector. DE: distal enhancer; PE: proximal enhancer. PP: Pou5f1 proximal promoter. The deleted regions are shown in gray. (b) The removal of the $2.5 \mathrm{~kb} 5^{\prime}$-flanking region (pOg2 vector) had no significant impact $(p>0.05)$ on the promoter activity in each cell line. However, the promoter activity was significantly decreased in the F9 cell line $(p<0.05)$ when the DE region was removed. An obvious drop of promoter activity was detected in the P19 cell line $(p<0.05)$ when the PE region was removed. Relative activity of each promoter construct is reflected by fluorescence intensity. Data are represented as the mean \pm SEM. $*$ indicates $p$ value $<0.05$ versus normal. $* *$ indicates $p$ value $<0.01$ versus normal. Similar results were observed in more than two independent experiments. 


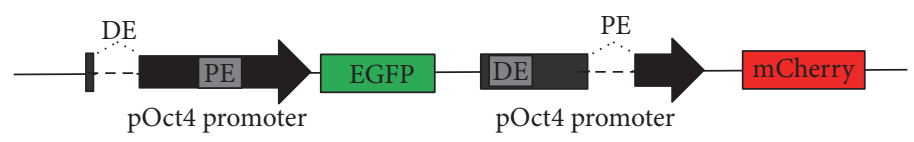

(a)

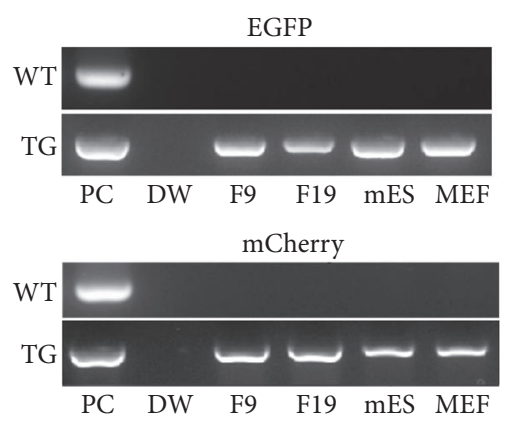

(b)

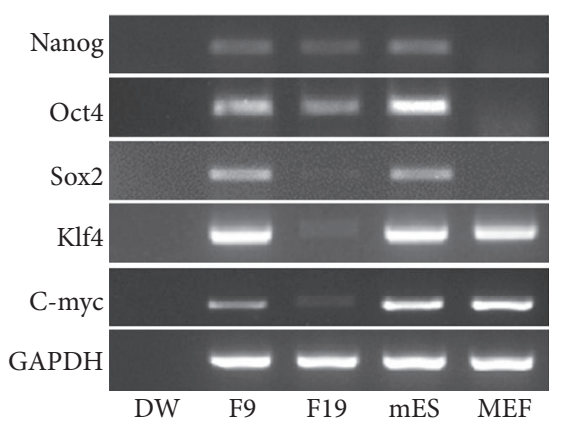

(c)
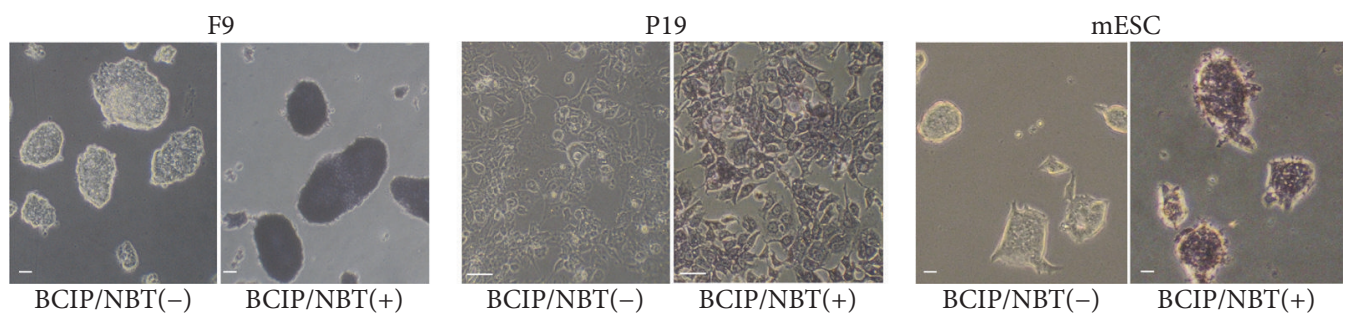

(d)
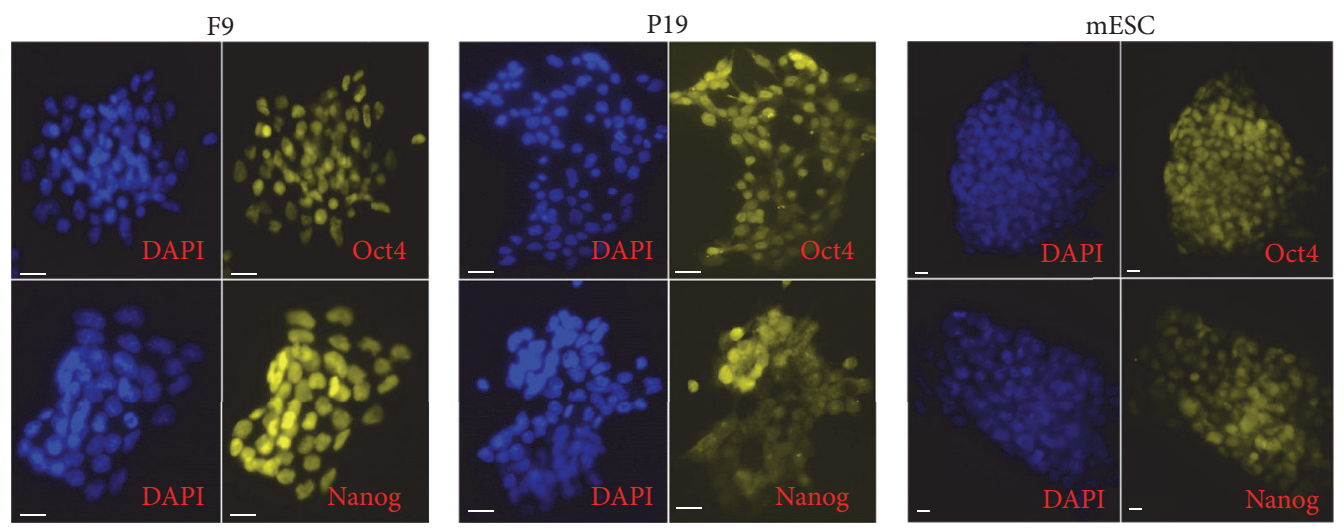

(e)

FIGURE 3: Establishment of transgenic cell lines stably expressing EGFP and mCherry (RFP). (a) A schematic illustration of the constructed $\triangle \mathrm{DE}-$ pOG2- $\triangle$ PE-pOm2 vector using the porcine Oct4 promoter. DE: distal enhancer; PE: proximal enhancer. (b) Genotyping the Oct4 promoter-driven transgenes from genomic DNA. PC: positive control; DW: distilled water, negative control; WT: wild type; TG: transgenic cell lines. Lanes 3-6, fluorescence-positive cell lines established from wild type F9 cells, P19 cells, mESCs, and MEFs. (c) Reverse transcriptional PCR analysis of pluripotency markers in fluorescence-positive cell lines. (d) Surface alkaline phosphatase activity in transgenic F9 cells, P19 cells, and mESCs was measured using BCIP/NBT. (e) Typical pluripotency markers, Nanog and Oct4, were assayed by immunofluorescent cytochemical staining in transgenic F9 cells, P19 cells, and mESCs. Scale bars indicate $20 \mu \mathrm{m}$.

fluorescence was detected in Type IV colonies. This result demonstrated that the culture population in a conventional mESC medium is heterogenous and the different subcell types can be classified by our dual-fluorescence reporter.

\section{Discussion}

The URS of a specific gene usually consists of enhancers in addition to a minimal proximal promoter (PP). An enhancer was first demonstrated in the early 1980s in SV40 [41]. It is a type of cis-regulatory element located in genomic DNA that can regulate gene expression through histone modifications [42]. Enhancers contain multiple cognate binding sites for a variety of transcription factors [43, 44]. Unlike promoters, enhancers can act near the core promoter (proximal enhancer) or over very long distances of more than several kilobases [45] or megabases [46] on the chromosome from their target gene (distal enhancer). 


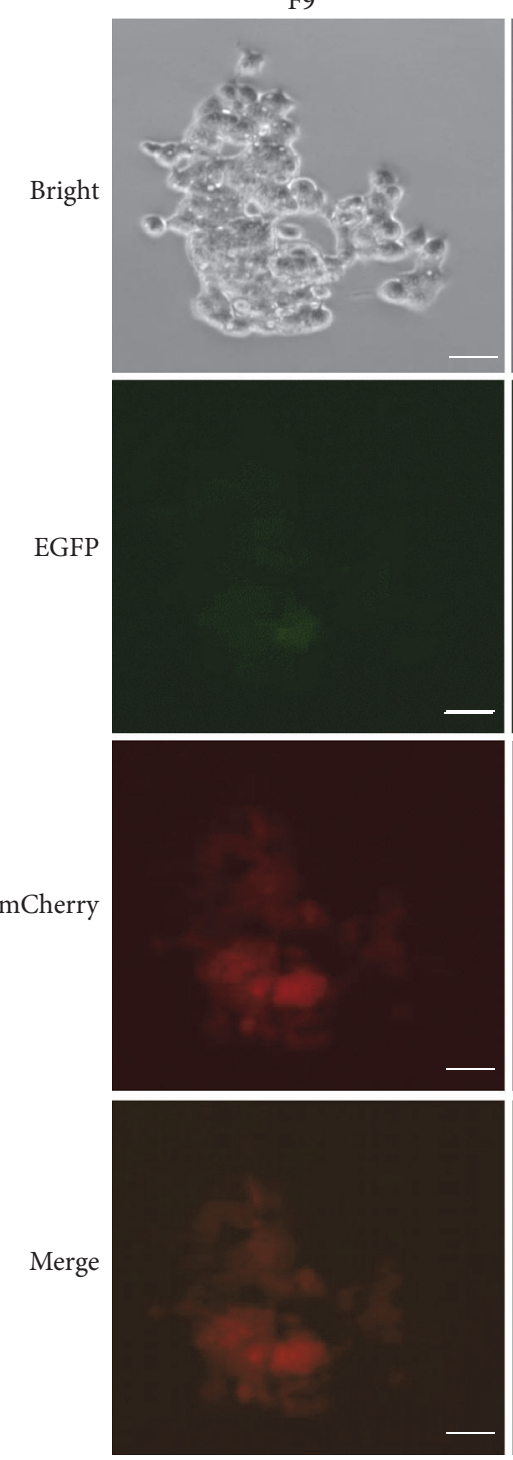

F9

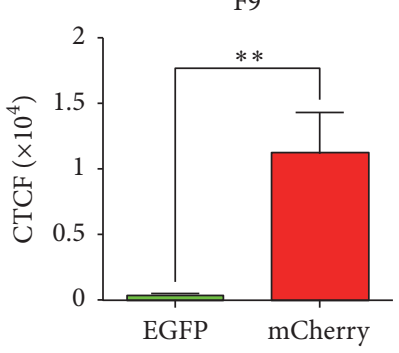

F19
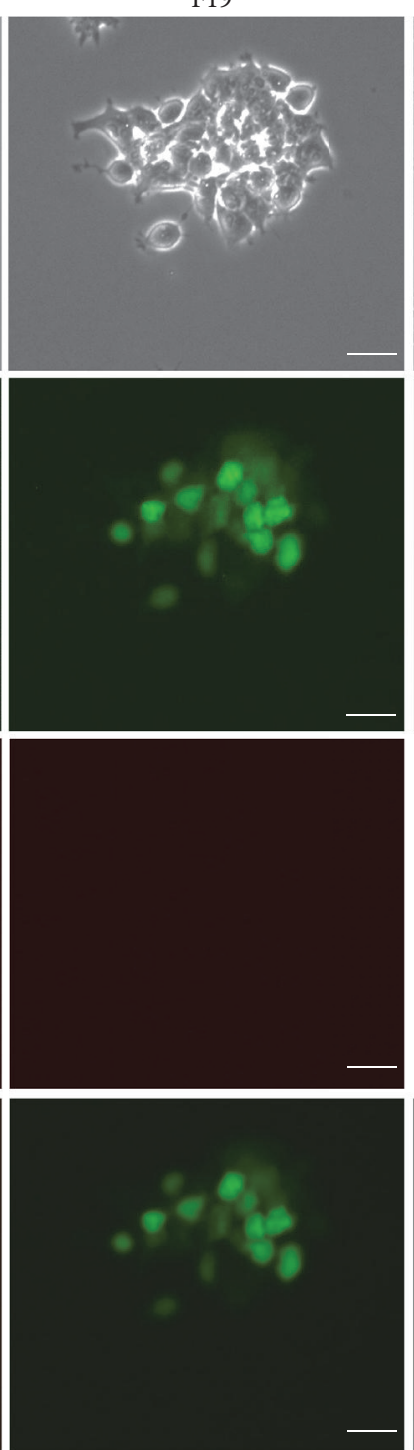

(a)

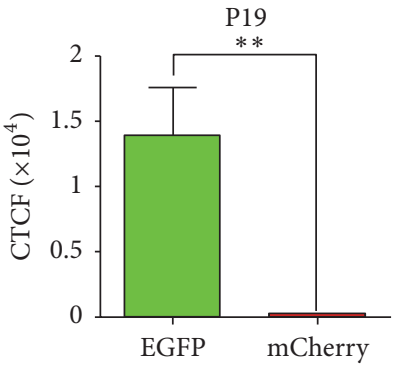

(b)
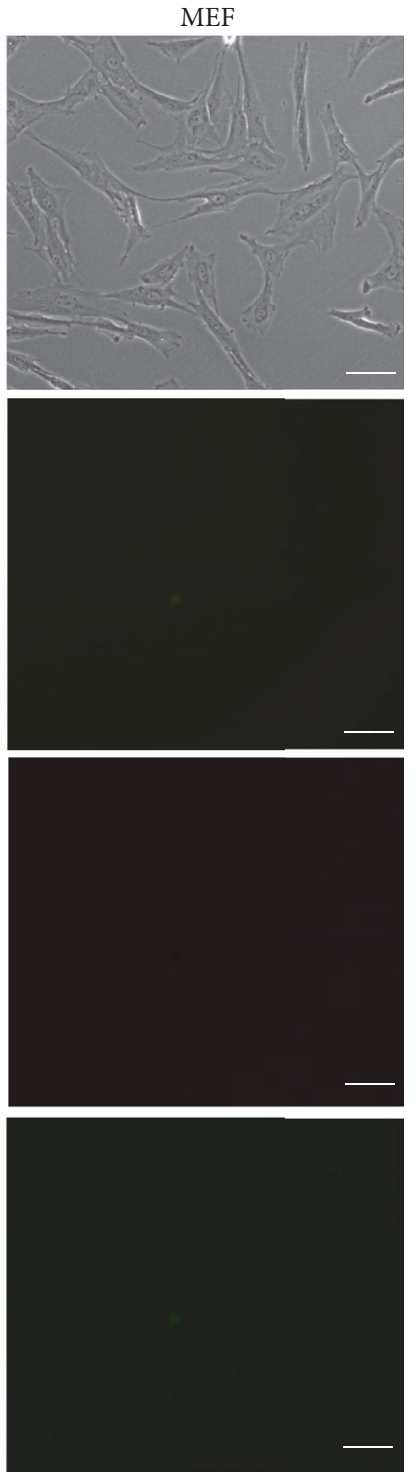

MEF

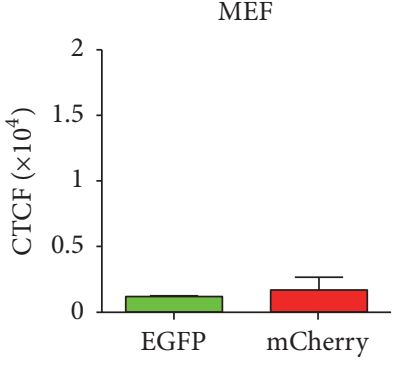

FIgURE 4: F9 cells and P19 cells exhibit completely different fluorescence signals. (a) The transgenic ESC-like F9 cells show a higher red fluorescence, while green fluorescence was primarily detected in EpiSC-like P19 cells. The negative control cell line, MEFs, exhibited neither green nor red fluorescence expression. (b) Quantitative analysis of the fluorescence intensity in a same cell clone. The fluorescence intensity of the pictures was converted to corrected total cell fluorescence (CTCF) by ImageJ $2 \mathrm{x}$ as previously described [35]. CTCF $=$ integrated density - (area of selected cell $\times$ mean fluorescence of background readings). Data are represented as the mean \pm SEM. $*$ indicates $p$ value $<0.05$ versus normal. $* *$ indicates $p$ value $<0.05$ versus normal. Similar results were observed in more than two independent experiments. Scale bars indicate $20 \mu \mathrm{m}$. 


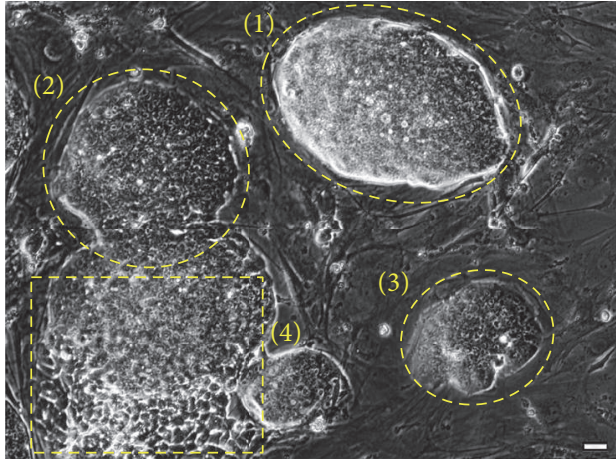

(a)
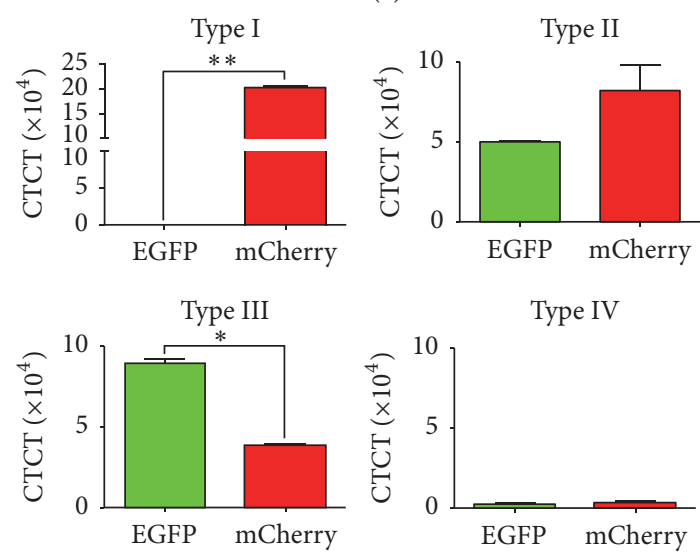

(c)
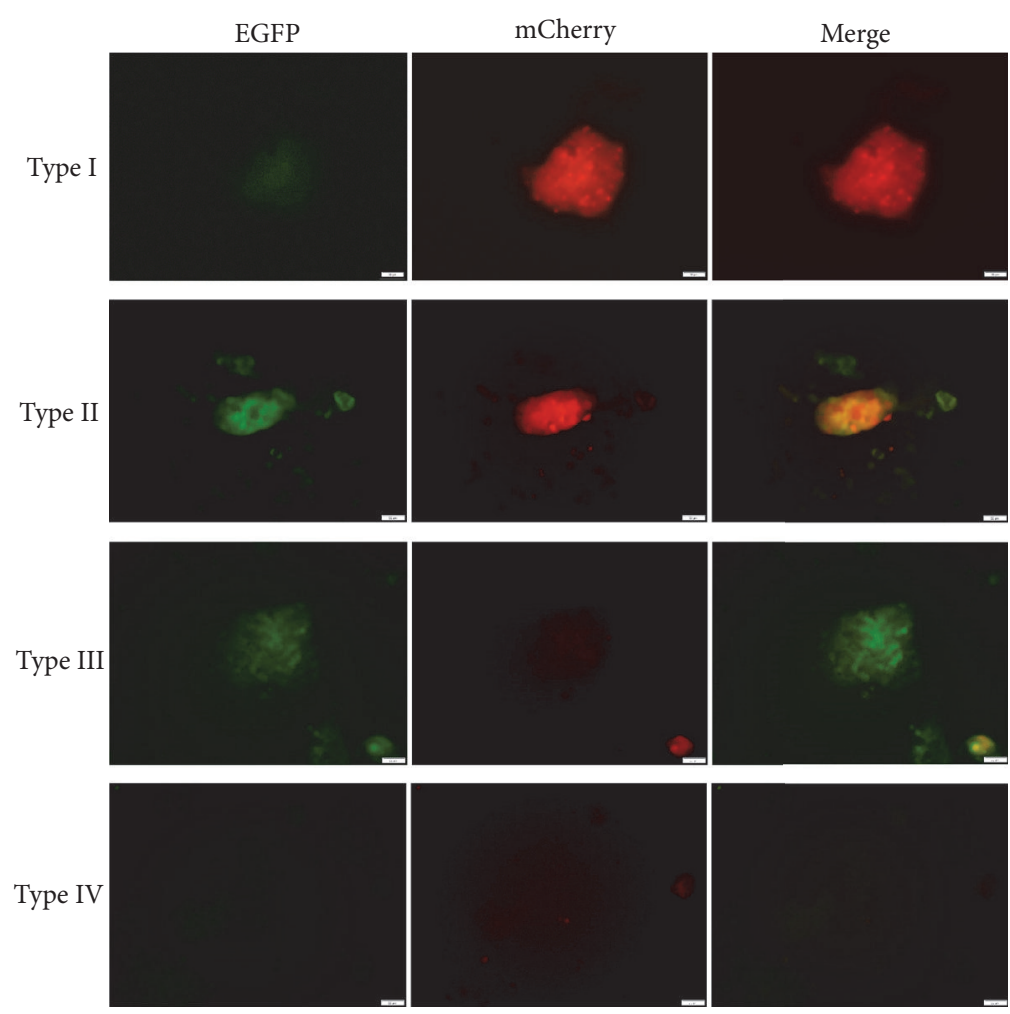

(b)

Figure 5: Classifying mESCs from a heterogenous population by dual-fluorescence signals. (a) When cultured in vitro, most ESC colonies exhibit a three-dimensional dome-like morphology (1), but a fraction of ESCs may spontaneously differentiate into flattened $(2,3)$ or rosettelike structures (4). (b) Four cell types were identified in transgenic mESCs. A relatively higher level of red fluorescence was detected in Type I cells. A similar level of green and red fluorescence was detected in Type II cells. A relatively higher level of green fluorescence was detected in Type III cells. Neither green nor red fluorescence is detected in Type IV cells. CTCF: corrected total cell fluorescence. (c) Quantitative analysis of the fluorescence intensity in the same cell clone. The fluorescence signal was scanned by Image and converted into numeric data for comparison of cell types. Scale bars indicate $50 \mu \mathrm{m}$. Data are represented as the mean \pm SEM. $*$ indicates $p$ value $<0.05$ versus normal. $* *$ indicates $p$ value $<0.05$ versus normal. Similar results were observed in more than two independent experiments.

Some genes are only expressed in a certain cell type or tissue because their promoter activities are regulated by celltype-specific enhancers $[47,48]$. It has been reported that a powerful distal enhancer located in the URS of the FGF4 gene can activate FGF4 transcription in F9 cells and ESCs through two cooperative transcription factors, Sox2 and Oct4 [49]. A similar study of mouse Oct4 showed that a distal enhancer could drive Oct4 expression in undifferentiated ESCs, morula, primordial germ cells, and ICM, whereas a proximal enhancer $(\mathrm{PE})$ can block its expression in the epiblast stage [33]. In humans, the Oct4 gene was reported to be expressed in both ICM and trophectoderm [50], which is similar to rabbit [51], goat [15], and cattle, but the conclusions conflict [14]. This phenomenon can be explained as hESCs are in a metastable epiblast-like state [52], which means a given culture condition may induce them into divergent fates [53]. For example, when hESCs were epigenetically reprogrammed to a more "naïve" undifferentiated mouse-ESC-like state, they showed a regulatory pattern similar to mESCs that predominantly utilize the Oct4 distal enhancer [54].
The expression pattern of pig Oct4 in early embryonic development was reported to be similar to humans but different from mouse [55]. In this study, we checked the URS of the pig Oct4 gene and found that although it is obviously different from other species, especially in the distribution of $\mathrm{CpG}$ dinucleotides, which are potential methylation sites that play important roles in regulating gene expression [56], the three functional regulatory boxes (DE, PE, and PP) are highly conserved. Therefore, we adopted the strategy of classifying the naive and primed PSCs using the DE and the PE characteristics in the mouse Oct4 URS and constructed a DE/PE-dependent dual-fluorescence reporter with the pig Oct4 URS.

There have been many studies on pig iPSCs to date. However, some of these reported iPSC lines resemble mouse EpiSCs with a compact and flat colony morphology and dependence on bFGF [57-59], which may be in a metastable pluripotent state similar to hESCs [60]. And the others are similar to mouse ESCs that have a packed dome-shaped appearance and are primarily dependent on $\operatorname{LIF}[24,61,62]$, 
which are thought to be in a more "naive" undifferentiated state [60]. More importantly, few of these putative iPSCs have been used to perform chimera studies [63]. Given this, we lack precise "authentic" or "naïve" pig PSCs for studying this reporter; instead, we first tested it in three types of defined mouse PSCs with different levels of pluripotency. As we expected, the primed-PSC-like P19 cells can be well distinguished from naïve-PSC-like F9 cells, and the heterogenous state mESCs can also be classified into at least 4 subcell types (Figures 4 and 5). Now, on one hand, we performed cell sorting through different fluorescence expression patterns and performed further analysis to verify that these 4 types of cells were different metastable state stem cells that have different pluripotency characteristics. On the other hand, we are currently testing this reporter by SCNT in pig embryo to complete the relative data for pigs.

In summary, we have cloned and characterized the pig Oct4 URS using an approach similar to mouse. And these findings are successfully used to construct a dualfluorescence reporter system, which has been proved effective in distinguishing three types of mouse PSCs. We expect that this reporter will also be a practical tool to distinguish porcine naïve and primed PSCs.

\section{Competing Interests}

The authors declare no competing interests.

\section{Acknowledgments}

This work was conducted with the support of "KRIBB Initiative Program" from Korea Research Institute of Bioscience \& Biotechnology (KRIBB) (Project no. KGM5221611) and "Next Generation Biogreen 21" from the Rural Development Administration, Republic of Korea (Project no. PJ0110412016).

\section{References}

[1] Y. Guo, L. Lei, X. Ma, and H. Wang, "Characterization of the proximal region of the goat NANOG promoter that is used for monitoring cell reprogramming and early embryo development," Veterinary Journal, vol. 199, no. 1, pp. 80-87, 2014.

[2] J. F. Zhong, L. Weiner, Y. Jin, W. Lu, and C. R. Taylor, "A realtime pluripotency reporter for human stem cells," Stem Cells and Development, vol. 19, no. 1, pp. 47-52, 2010.

[3] S. Lai, S. Wei, B. Zhao et al., "Generation of knock-in pigs carrying Oct4-tdTomato reporter through CRISPR/Cas9-mediated genome engineering," PLoS ONE, vol. 11, no. 1, Article ID e0146562, 2016.

[4] M. Nowak-Imialek and H. Niemann, "Oct4-EGFP transgenic pigs as a new tool for visualization of pluripotent and reprogrammed cells," in Cell and Molecular Biology and Imaging of Stem Cells, H. Schatten, Ed., chapter 5, p. 304, John Wiley \& Sons, Hoboken, NJ, USA, 2014.

[5] S. Jerabek, F. Merino, H. R. Schöler, and V. Cojocaru, "OCT4: dynamic DNA binding pioneers stem cell pluripotency," Biochimica et Biophysica Acta, vol. 1839, no. 3, pp. 138-154, 2014.
[6] M. Stadtfeld and K. Hochedlinger, "Induced pluripotency: history, mechanisms, and applications," Genes \& Development, vol. 24, no. 20, pp. 2239-2263, 2010.

[7] W. H. Krueger, B. Tanasijevic, C. Norris, X. C. Tian, and T. P. Rasmussen, "Oct4 promoter activity in stem cells obtained through somatic reprogramming," Cellular Reprogramming, vol. 15, no. 2, pp. 151-158, 2013.

[8] I. Grabundzija, J. Wang, A. Sebe et al., "Sleeping Beauty transposon-based system for cellular reprogramming and targeted gene insertion in induced pluripotent stem cells," Nucleic Acids Research, vol. 41, no. 3, pp. 1829-1847, 2013.

[9] T. Yoshimizu, N. Sugiyama, M. De Felice et al., "Germlinespecific expression of the Oct-4/green fluorescent protein (GFP) transgene in mice," Development Growth and Differentiation, vol. 41, no. 6, pp. 675-684, 1999.

[10] Y. Li, Q. Zhang, X. Yin et al., "Generation of iPSCs from mouse fibroblasts with a single gene, Oct4, and small molecules," Cell Research, vol. 21, no. 1, pp. 196-204, 2011.

[11] P. Hou, Y. Li, X. Zhang et al., "Pluripotent stem cells induced from mouse somatic cells by small-molecule compounds," Science, vol. 341, no. 6146, pp. 651-654, 2013.

[12] L. Gerrard, D. Zhao, A. J. Clark, and W. Cui, "Stably transfected human embryonic stem cell clones express OCT4specific green fluorescent protein and maintain self-renewal and pluripotency," Stem Cells, vol. 23, no. 1, pp. 124-133, 2005.

[13] S. Ruiz, A. D. Panopoulos, N. Montserrat et al., "Generation of a drug-inducible reporter system to study cell reprogramming in human cells," Journal of Biological Chemistry, vol. 287, no. 48, pp. 40767-40778, 2012.

[14] D. K. Berg, C. S. Smith, D. J. Pearton et al., "Trophectoderm lineage determination in cattle," Developmental Cell, vol. 20, no. 2, pp. 244-255, 2011.

[15] L. Lei, L. Li, F. Du, C.-H. Chen, H. Wang, and C. L. Keefer, "Monitoring bovine fetal fibroblast reprogramming utilizing a bovine NANOG promoter-driven EGFP reporter system," Molecular Reproduction and Development, vol. 80, no. 3, pp.193203, 2013.

[16] M. Yin, Z. Fang, W. Jiang et al., “The Oct4 promoter-EGFP transgenic rabbit: a new model for monitoring the pluripotency of rabbit stem cells," The International Journal of Developmental Biology, vol. 57, no. 11-12, pp. 845-852, 2013.

[17] L. Quan, Y. Chen, J. Song et al., "Establishment of a rabbit Oct4 promoter-based EGFP reporter system," PLoS ONE, vol. 9, no. 10, Article ID e109728, 2014.

[18] H. Kato, K. Abe, S. Yokota et al., "Establishment of oct4:gfp transgenic zebrafish line for monitoring cellular multipotency by GFP fluorescence," In Vitro Cellular \& Developmental Biology-Animal, vol. 51, no. 1, pp. 42-49, 2015.

[19] A. Froschauer, M. M. Khatun, D. Sprott et al., "oct4-EGFP reporter gene expression marks the stem cells in embryonic development and in adult gonads of transgenic medaka," Molecular Reproduction and Development, vol. 80, no. 1, pp. 48-58, 2013.

[20] M. Nowak-Imialek, W. A. Kues, B. Petersen et al., "Oct4enhanced green fluorescent protein transgenic pigs: a new large animal model for reprogramming studies," Stem Cells and Development, vol. 20, no. 9, pp. 1563-1575, 2011.

[21] L. Huang, N. Fan, J. Cai et al., "Establishment of a porcine Oct-4 promoter-driven EGFP reporter system for monitoring pluripotency of porcine stem cells," Cellular Reprogramming, vol. 13, no. 2, pp. 93-98, 2011. 
[22] J. Nichols and A. Smith, "Naive and primed pluripotent states," Cell Stem Cell, vol. 4, no. 6, pp. 487-492, 2009.

[23] L. Weinberger, M. Ayyash, N. Novershtern, and J. H. Hanna, "Dynamic stem cell states: naive to primed pluripotency in rodents and humans," Nature Reviews Molecular Cell Biology, vol. 17, no. 3, pp. 155-169, 2016.

[24] Y. Zhang, C. Wei, P. Zhang et al., "Efficient reprogramming of naïv-like induced pluripotent stem cells from porcine adiposederived stem cells with a feeder-independent and serum-free system," PLoS ONE, vol. 9, no. 1, Article ID e85089, 2014.

[25] C. Buecker and N. Geijsen, "Different flavors of pluripotency, molecular mechanisms, and practical implications," Cell Stem Cell, vol. 7, no. 5, pp. 559-564, 2010.

[26] J. Hanna, A. W. Cheng, K. Saha et al., "Human embryonic stem cells with biological and epigenetic characteristics similar to those of mouse ESCs," Proceedings of the National Academy of Sciences of the United States of America, vol. 107, no. 20, pp. 92229227, 2010.

[27] H. W. Choi, J. S. Kim, S. Choi et al., "Neural stem cells differentiated from iPS cells spontaneously regain pluripotency," Stem Cells, vol. 32, no. 10, pp. 2596-2604, 2014.

[28] S.-H. Fujishiro, K. Nakano, Y. Mizukami et al., "Generation of naive-like porcine-induced pluripotent stem cells capable of contributing to embryonic and fetal development," Stem Cells and Development, vol. 22, no. 3, pp. 473-482, 2013.

[29] Y. S. Manor, R. Massarwa, and J. H. Hanna, "Establishing the human naïve pluripotent state," Current Opinion in Genetics and Development, vol. 34, pp. 35-45, 2015.

[30] Y. Liu, Y. Ma, J.-Y. Yang et al., "Comparative gene expression signature of pig, human and mouse induced pluripotent stem cell lines reveals insight into pig pluripotency gene networks," Stem Cell Reviews and Reports, vol. 10, no. 2, pp. 162-176, 2014.

[31] R. Ghorbani, A. Emamzadeh, V. Khazaie et al., "Constructing a mouse Oct4 promoter/EGFP vector, as a whole-cellular reporter to monitor the pluripotent state of cells," Avicenna Journal of Medical Biotechnology, vol. 5, no. 1, pp. 2-9, 2013.

[32] J. Y. Joo, H. W. Choi, M. J. Kim et al., "Establishment of a primed pluripotent epiblast stem cell in FGF4-based conditions," Scientific Reports, vol. 4, article 7477, 2014.

[33] Y. I. I. Yeom, G. Fuhrmann, C. E. Ovitt et al., "Germline regulatory element of Oct-4 specific for the totipotent cycle of embryonal cells," Development, vol. 122, no. 3, pp. 881-894, 1996.

[34] A. Gillich, S. Bao, N. Grabole et al., "Epiblast stem cell-based system reveals reprogramming synergy of germline factors," Cell Stem Cell, vol. 10, no. 4, pp. 425-439, 2012.

[35] B. S. Ko, T. C. Chang, S. K. Shyue, Y. C. Chen, and J. Y. Liou, "An efficient transfection method for mouse embryonic stem cells," Gene Therapy, vol. 16, no. 1, pp. 154-158, 2009.

[36] V. Nordhoff, K. Hübner, A. Bauer, I. Orlova, A. Malapetsa, and H. R. Schöler, "Comparative analysis of human, bovine, and murine Oct- 4 upstream promoter sequences," Mammalian Genome, vol. 12, no. 4, pp. 309-317, 2001.

[37] K. A. Frazer, L. Pachter, A. Poliakov, E. M. Rubin, and I. Dubchak, "VISTA: computational tools for comparative genomics," Nucleic Acids Research, vol. 32, pp. W273-W279, 2004.

[38] J. Dimberg, T. T. Hong, M. Skarstedt, S. Löfgren, N. Zar, and A. Matussek, "Analysis of APC and IGFBP7 promoter gene methylation in Swedish and Vietnamese colorectal cancer patients," Oncology Letters, vol. 5, no. 1, pp. 25-30, 2012.
[39] G. Dravid, H. Hammond, and L. Cheng, "Culture of human embryonic stem cells on human and mouse feeder cells," Methods in Molecular Biology, vol. 331, pp. 91-104, 2006.

[40] H. Estomba, I. Muñoa-Hoyos, M. Gianzo et al., "Expression and localization of opioid receptors in male germ cells and the implication for mouse spermatogenesis," PLOS ONE, vol. 11, no. 3, Article ID e0152162, 2016.

[41] J. Banerji, S. Rusconi, and W. Schaffner, "Expression of a $\beta$ globin gene is enhanced by remote SV40 DNA sequences," Cell, vol. 27, no. 2, pp. 299-308, 1981.

[42] J. O. Yáñez-Cuna, C. D. Arnold, G. Stampfel et al., "Dissection of thousands of cell type-specific enhancers identifies dinucleotide repeat motifs as general enhancer features," Genome Research, vol. 24, no. 7, pp. 1147-1156, 2014.

[43] M. Bulger and M. Groudine, "Functional and mechanistic diversity of distal transcription enhancers," Cell, vol. 144, no. 3, pp. 327-339, 2011.

[44] X. Gao, J. Yang, J. C. H. Tsang, J. Ooi, D. Wu, and P. Liu, "Reprogramming to pluripotency using designer TALE transcription factors targeting enhancers," Stem Cell Reports, vol. 1, no. 2, pp. 183-197, 2013.

[45] T. Vavouri, G. K. McEwen, A. Woolfe, W. R. Gilks, and G. Elgar, "Defining a genomic radius for long-range enhancer action: duplicated conserved non-coding elements hold the key," Trends in Genetics, vol. 22, no. 1, pp. 5-10, 2006.

[46] H. Y. Zhou, Y. Katsman, N. K. Dhaliwal et al., "A Sox2 distal enhancer cluster regulates embryonic stem cell differentiation potential," Genes and Development, vol. 28, no. 24, pp. 26992711, 2014.

[47] C.-T. Ong and V. G. Corces, "Enhancer function: new insights into the regulation of tissue-specific gene expression," Nature Reviews Genetics, vol. 12, no. 4, pp. 283-293, 2011.

[48] N. D. Heintzman, G. C. Hon, R. D. Hawkins et al., "Histone modifications at human enhancers reflect global cell-typespecific gene expression," Nature, vol. 459, no. 7243, pp. 108-112, 2009.

[49] A. Rizzino and E. L. Wuebben, "Sox2/Oct4: a delicately balanced partnership in pluripotent stem cells and embryogenesis," Biochimica et Biophysica Acta (BBA)-Gene Regulatory Mechanisms, vol. 1859, no. 6, pp. 780-791, 2016.

[50] G. Cauffman, H. Van de Velde, I. Liebaers, and A. Van Steirteghem, "Oct-4 mRNA and protein expression during human preimplantation development," Molecular Human Reproduction, vol. 11, no. 3, pp. 173-181, 2005.

[51] J. Kobolak, K. Kiss, Z. Polgar et al., "Promoter analysis of the rabbit POU5F1 gene and its expression in preimplantation stage embryos," BMC Molecular Biology, vol. 10, article 88, 2009.

[52] J. Itskovitz-Eldor, "A panel of glycan cell surface markers define pluripotency state and promote safer cell-based therapies," Cell Stem Cell, vol. 9, no. 4, pp. 291-292, 2011.

[53] A.-C. Veillard, H. Marks, A. S. Bernardo et al., "Stable methylation at promoters distinguishes epiblast stem cells from embryonic stem cells and the in vivo epiblasts," Stem Cells and Development, vol. 23, no. 17, pp. 2014-2029, 2014.

[54] O. Gafni, L. Weinberger, A. A. Mansour et al., "Derivation of novel human ground state naive pluripotent stem cells," Nature, vol. 504, no. 7479, pp. 282-286, 2013.

[55] N. Kirchhof, J. W. Carnwath, E. Lemme, K. Anastassiadis, H. Scholer, and H. Niemann, "Expression pattern of Oct-4 in preimplantation embryos of different species," Biology of Reproduction, vol. 63, no. 6, pp. 1698-1705, 2000. 
[56] S. Saxonov, P. Berg, and D. L. Brutlag, "A genome-wide analysis of $\mathrm{CpG}$ dinucleotides in the human genome distinguishes two distinct classes of promoters," Proceedings of the National Academy of Sciences of the United States of America, vol. 103, no. 5, pp. 1412-1417, 2006.

[57] D. Cheng, Y. Guo, Z. Li et al., "Porcine induced pluripotent stem cells require LIF and maintain their developmental potential in early stage of embryos," PLoS ONE, vol. 7, no. 12, Article ID e51778, 2012.

[58] F. D. West, S. L. Terlouw, D. J. Kwon et al., "Porcine induced pluripotent stem cells produce chimeric offspring," Stem Cells and Development, vol. 19, no. 8, pp. 1211-1220, 2010.

[59] Z. Wu, J. Chen, J. Ren et al., "Generation of pig induced pluripotent stem cells with a drug-inducible system," Journal of Molecular Cell Biology, vol. 1, no. 1, pp. 46-54, 2009.

[60] H. J. Jang, J. S. Kim, H. W. Choi et al., "Neural stem cells derived from epiblast stem cells display distinctive properties," Stem Cell Research, vol. 12, no. 2, pp. 506-516, 2014.

[61] Q. Gu, J. Hao, T. Hai et al., "Efficient generation of mouse ESCslike pig induced pluripotent stem cells," Protein and Cell, vol. 5, no. 5, pp. 338-342, 2014.

[62] W. Zhang, Y. Pei, L. Zhong, B. Wen, S. Cao, and J. Han, "Pluripotent and metabolic features of two types of porcine iPSCs derived from defined mouse and human ES cell culture conditions," PLoS ONE, vol. 10, no. 4, article e0124562, 2015.

[63] J. O. Secher, H. Callesen, K. K. Freude, and P. Hyttel, "Initial embryology and pluripotent stem cells in the pig-The quest for establishing the pig as a model for cell therapy," Theriogenology, vol. 85, no. 1, pp. 162-171, 2016. 

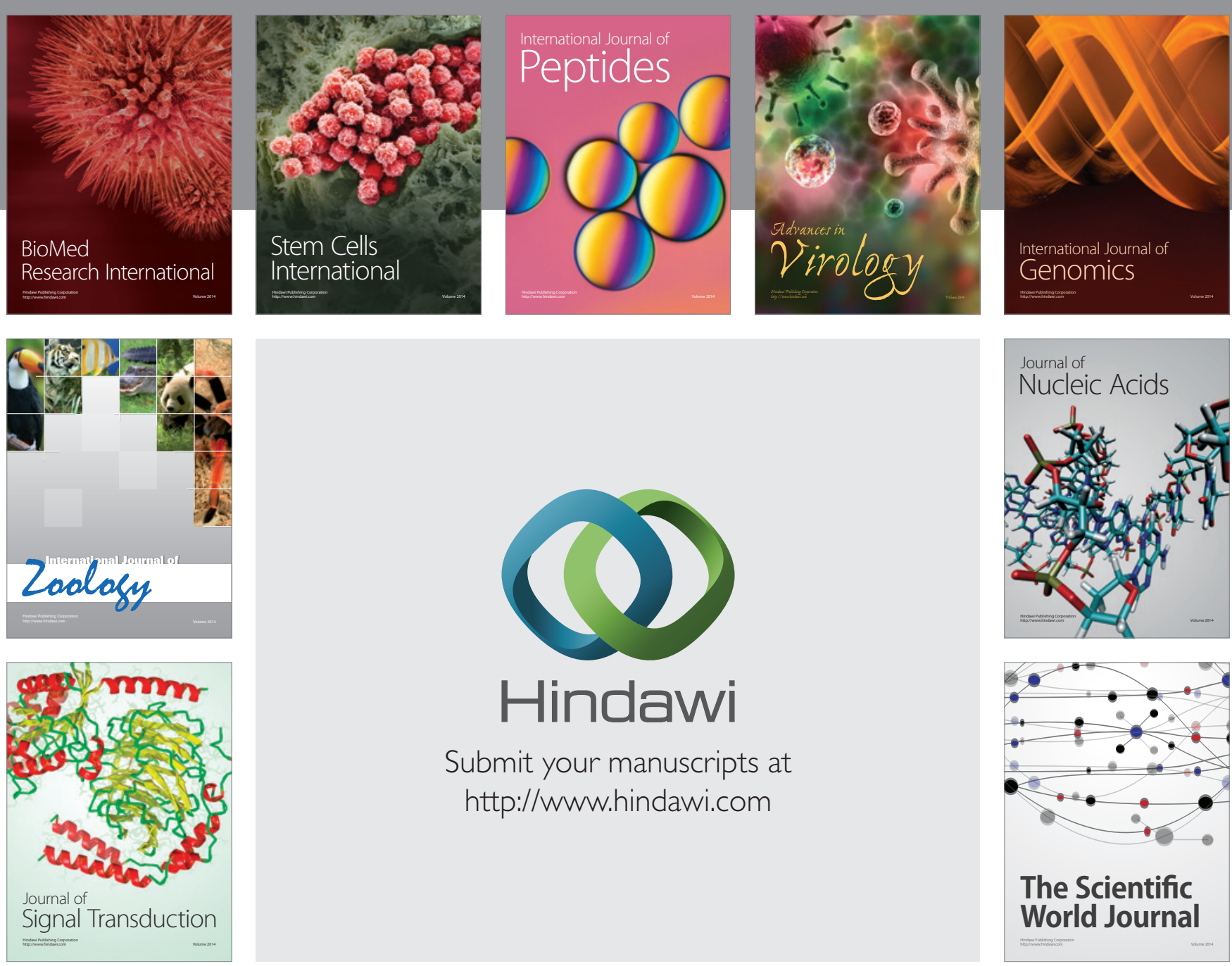

Submit your manuscripts at

http://www.hindawi.com
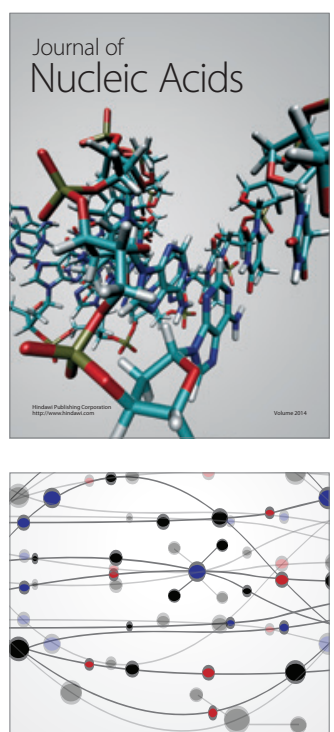

The Scientific World Journal
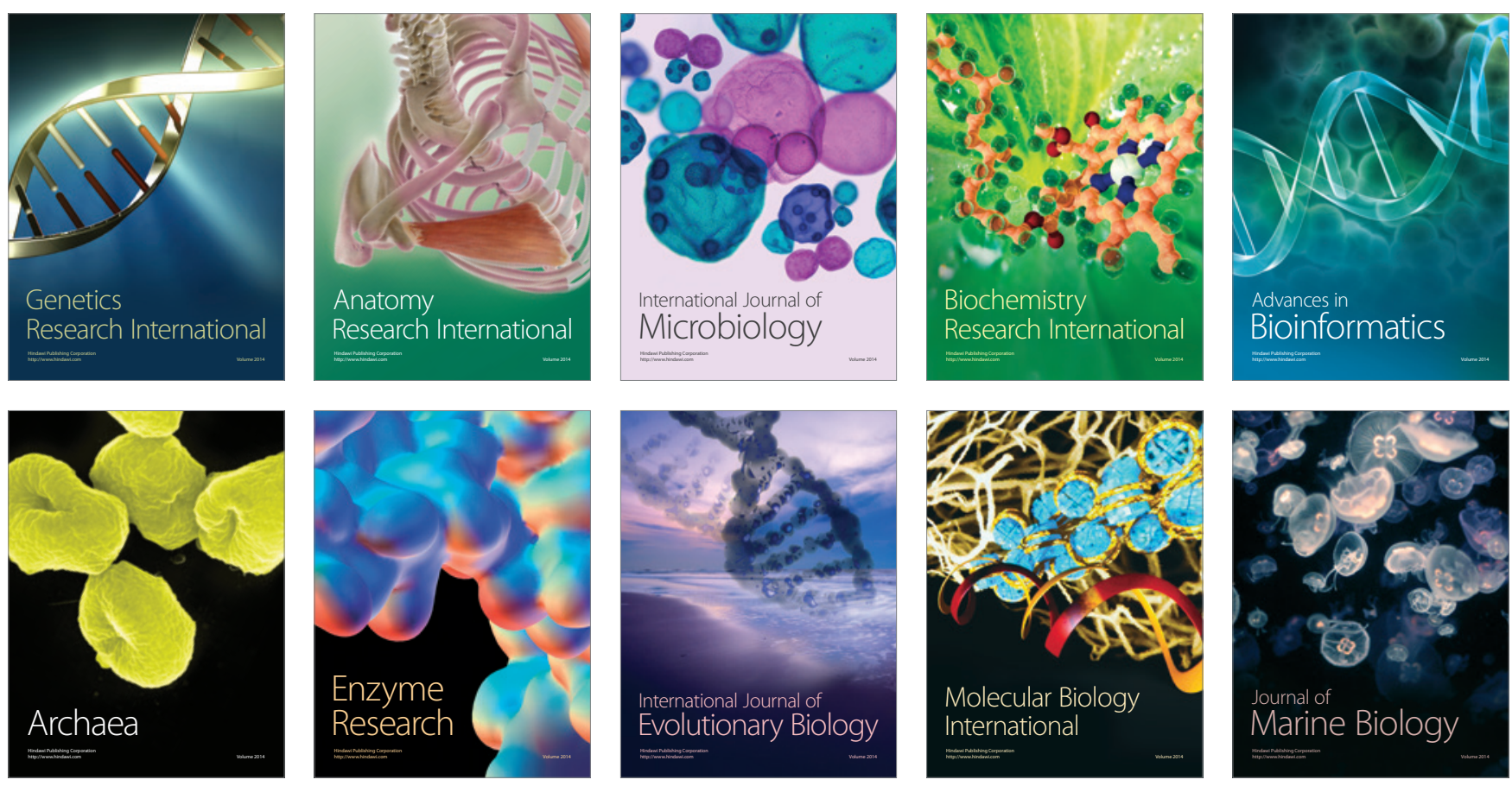